\title{
Hierarchical Au Nanoisland Arrays for Anti- Counterfeiting Surface-Enhanced Raman Scattering Stamps
}

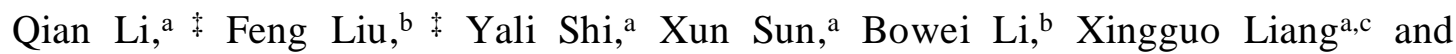
Guoqing Wang, ${ }^{* a, c}$

${ }^{a}$ College of Food Science \& Engineering, Ocean University of China, 5 Yushan, Road, Qingdao 266003, China

${ }^{b}$ Key Laboratory of Coastal Zone Environmental Processes, CAS, Shandong Provincial Key Laboratory of Coastal Zone Environmental Processes, Yantai Institute of Coastal Zone Research, Chinese Academy of Sciences, Yantai 264003, China

${ }^{c}$ Laboratory for Marine Drugs and Bioproducts, Pilot National Laboratory for Marine Science and Technology (Qingdao), Qingdao 266237, China

†These authors contributed equally.

*Corresponding author. E-mail: gqwang@ouc.edu.cn 


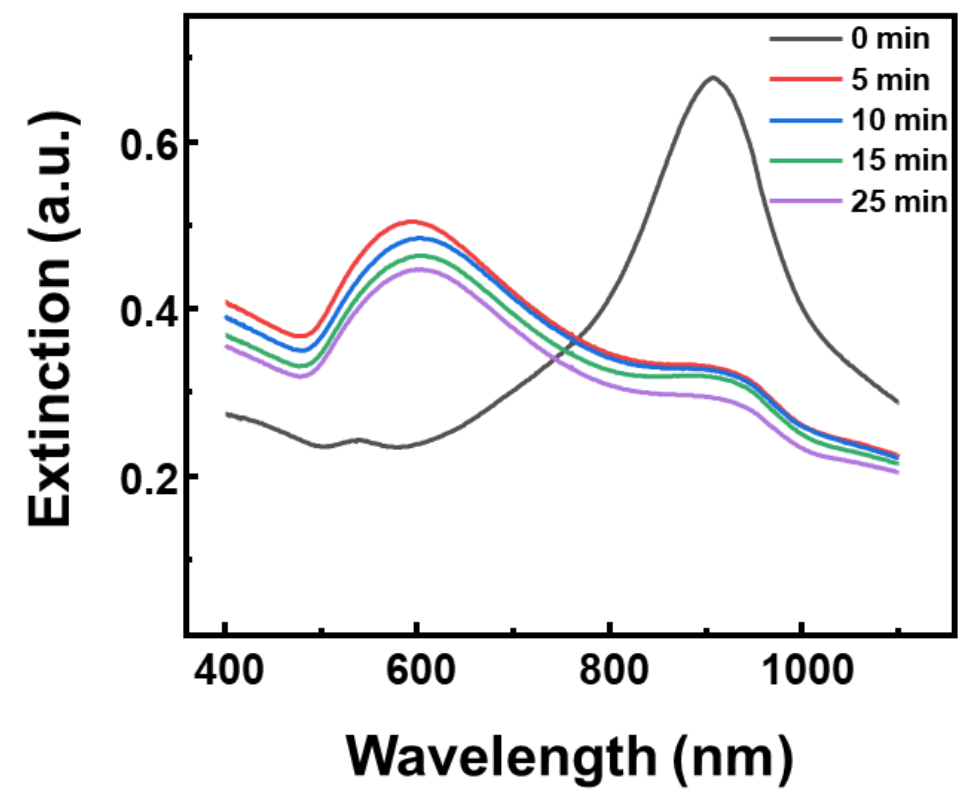

Figure S1 Time-course spectral measurement for the growing Au nanoisland arrays. The decrease in the spectral intensity after growth for $5 \mathrm{~min}$ may be attributed to aggregation of the large nanostructures or their adsorption onto the vessel. 

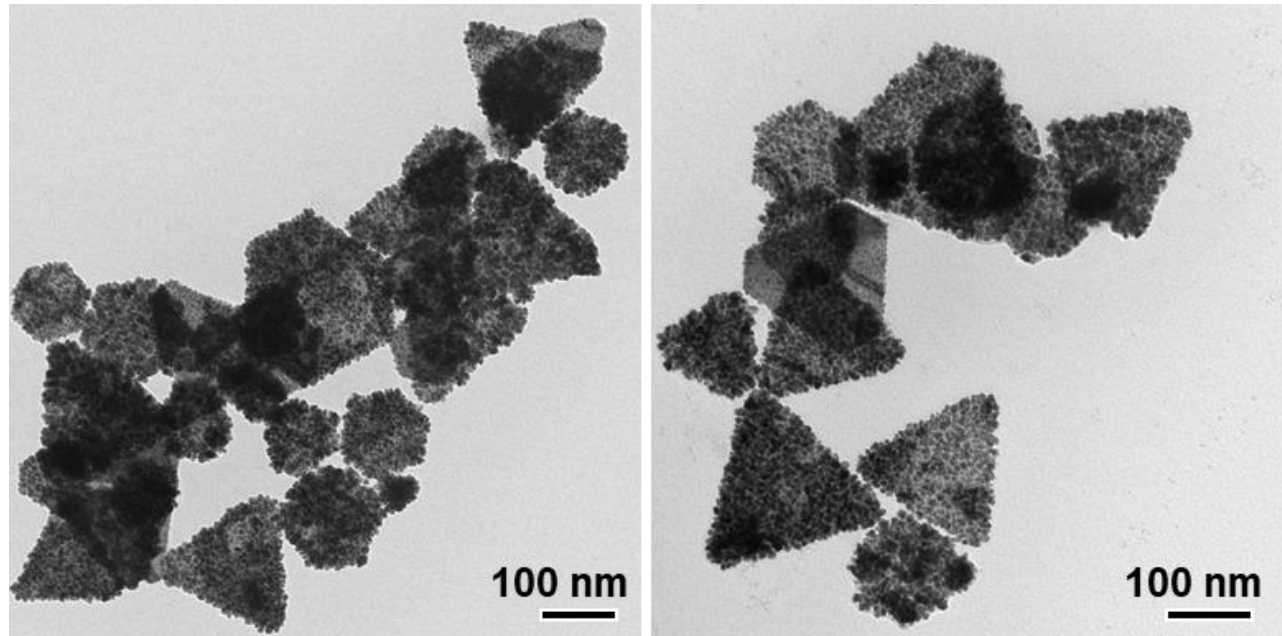

Figure S2 Typical TEM images of the Au nanoisland arrays obtained through quick injection-induced one-step growth. 

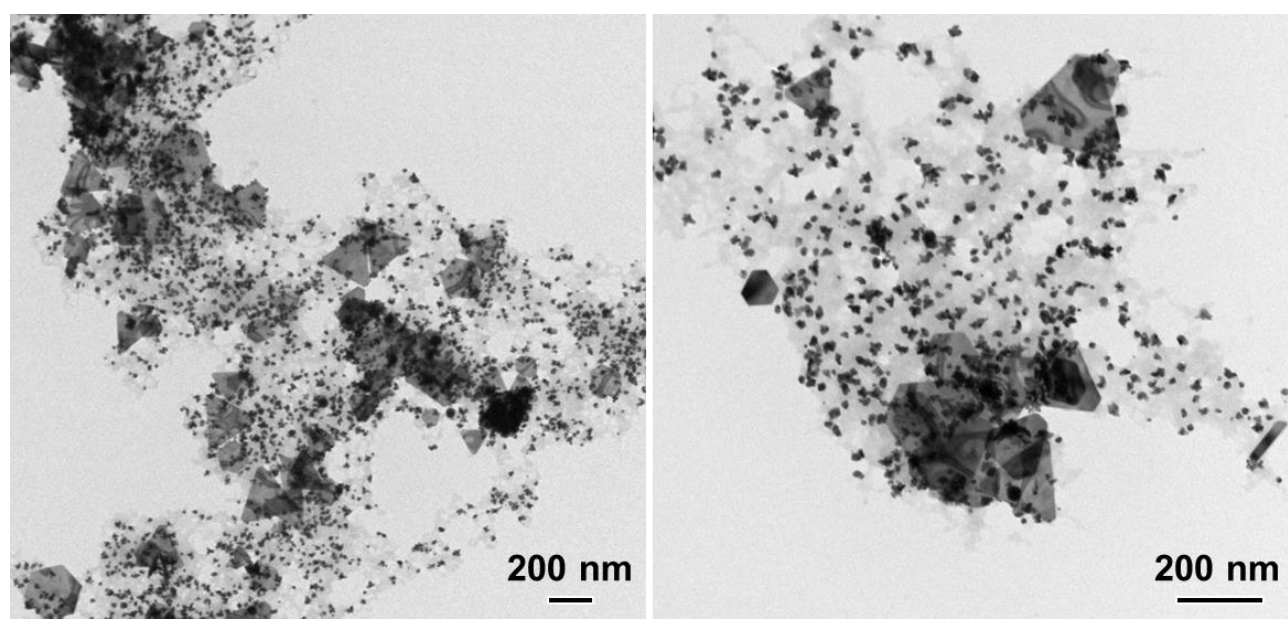

Figure S3 TEM images of the Au nanostructures in different magnifications produced by growth in presence of $0.01 \mu \mathrm{M} \mathrm{MA}$. 
Table S1 Summary of the size and inter-island distance of the nanoislands on the $\mathrm{Au}$ nanoplates obtained at different reaction times.

\begin{tabular}{llll}
\hline Growth conditions & Size / nm & Distance / nm & $\begin{array}{l}\text { Number of } \\
\text { islands studied }\end{array}$ \\
\hline $60 \mu \mathrm{M} \mathrm{MA}, 200 \mu \mathrm{M} \mathrm{HAuCl}_{4}$ & $5.2 \pm 1.2$ & 1.7 & 198 \\
$300 \mu \mathrm{M} \mathrm{MA}, 200 \mu \mathrm{M} \mathrm{HAuCl}_{4}$ & $11.1 \pm 4.0$ & 3.0 & 98 \\
$5 \mu \mathrm{M} \mathrm{ME}, 200 \mu \mathrm{M} \mathrm{HAuCl}_{4}$ & $9.1 \pm 2.3$ & 2.0 & 71 \\
$15 \mu \mathrm{M} \mathrm{MBIA,} 75 \mu \mathrm{M} \mathrm{HAuCl}_{4}$ & $6.0 \pm 1.6$ & 2.5 & 178 \\
\hline
\end{tabular}




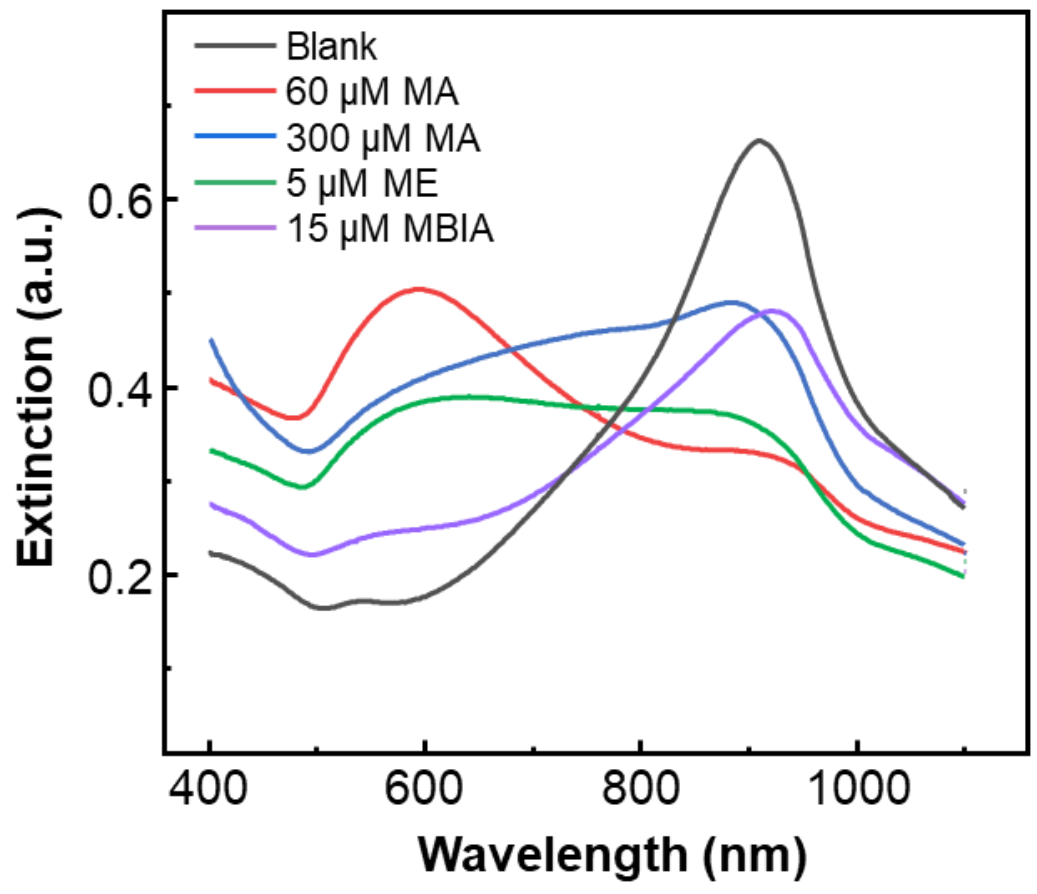

Figure S4 Extinction spectra of the Au nanoplate (blank) and the various $\mathrm{Au}$ nanoisland arrays produced under the ligand conditions of $60 \mu \mathrm{M}$ MA (red), $300 \mu \mathrm{M}$ MA (blue), $5 \mu \mathrm{M}$ ME (green) and $15 \mu \mathrm{M}$ MBIA (purple). The corresponding TEM images can refer to Figure 1b, Figure $2 \mathrm{c}$ and Figure 3. 

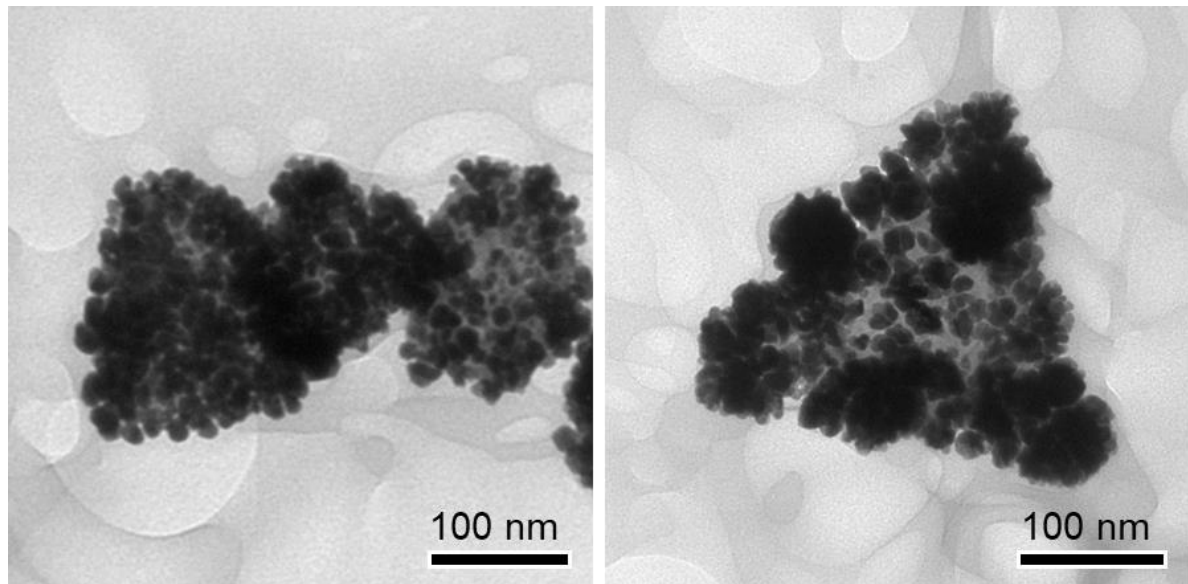

Figure S5 TEM images of the resultant Au nanostructures by growth in the presence of $100 \mu \mathrm{M}$ MBIA. 


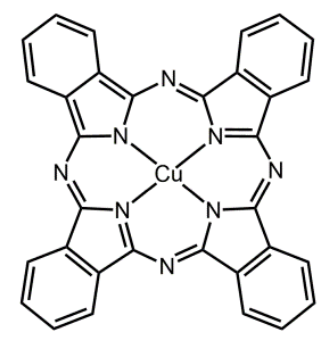

CuPC

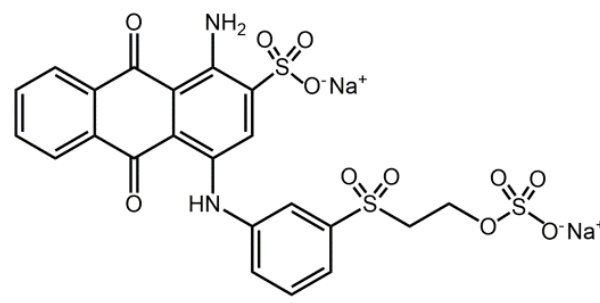

RB19<smiles>CN(C)c1ccc2c(c1)[SH](=O)=c1cc(N(C)C)ccc1=N2</smiles>

MB

Figure S6 Chemical structures of the dyes adopted for construct the SERS inks in the study. 
a

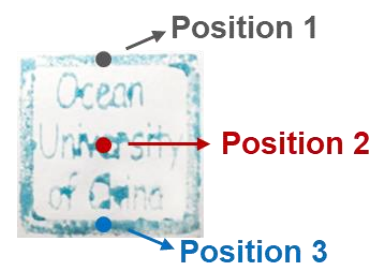

b
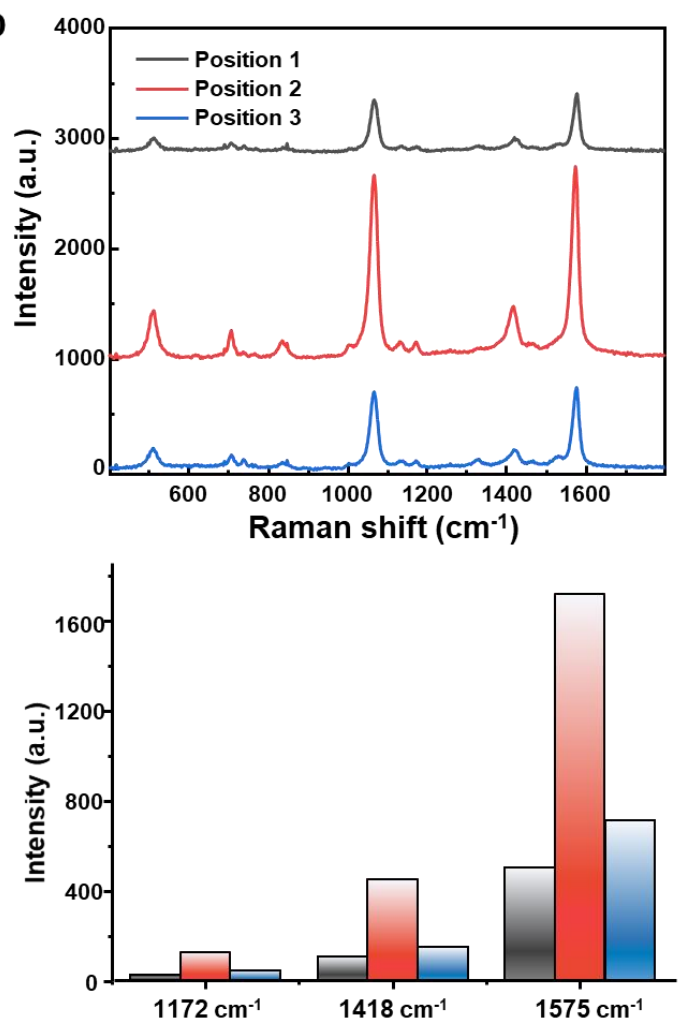
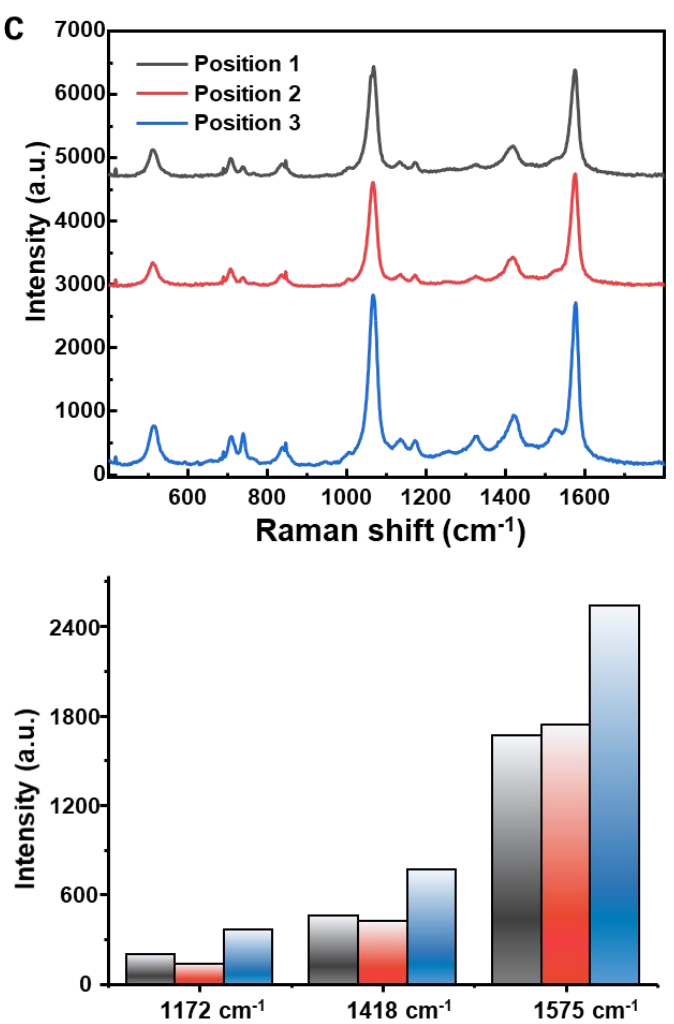

Figure S7 (a) The detection spots on the MB-based SERS stamp, and (b-c) the corresponding SERS spectra (top) and histograms for SERS intensity comparison at different bands (bottom) acquired before (b) and after (c) 23 day-treatment. 

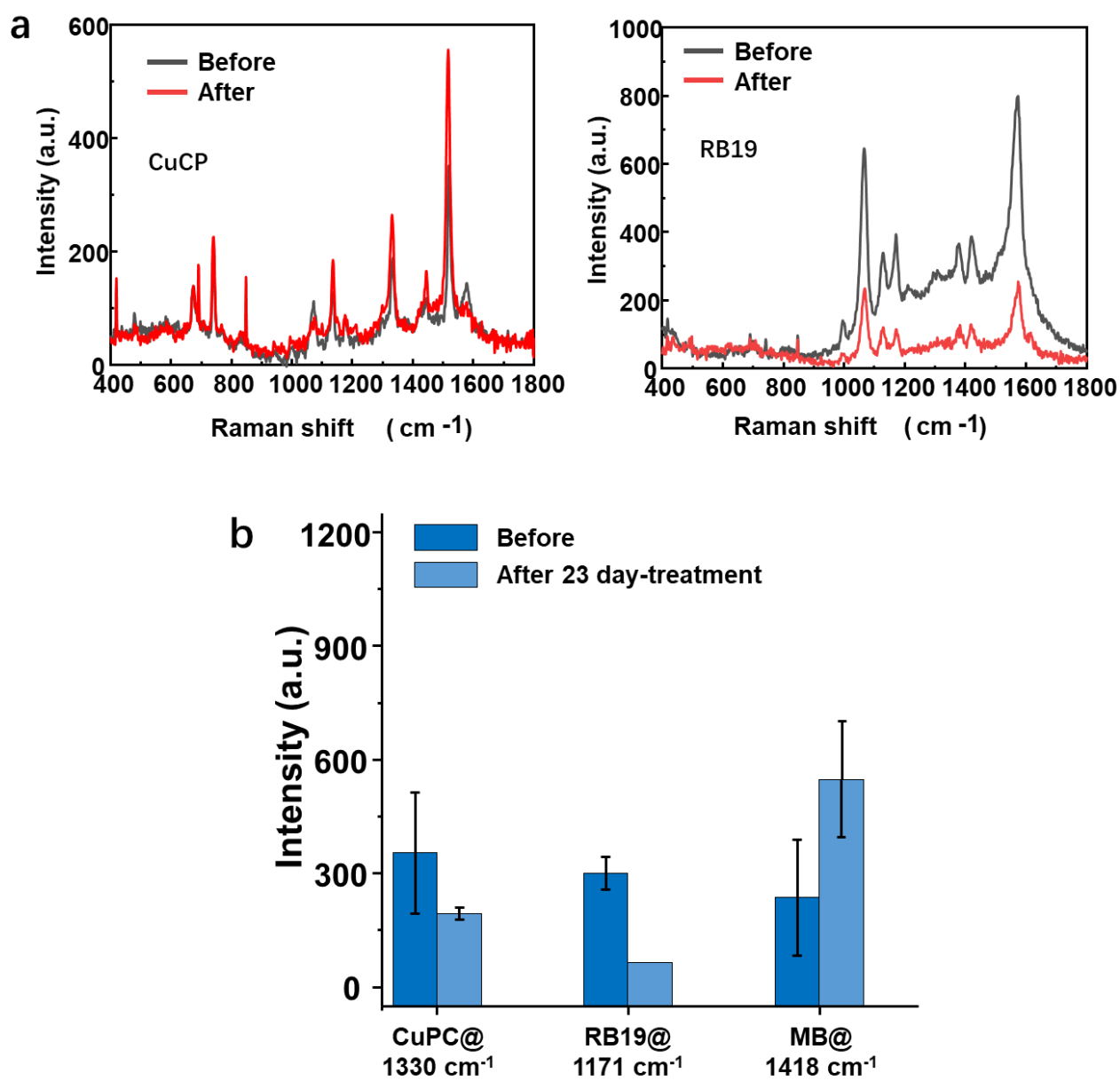

Figure S8 (a) Typical SERS spectra collected for the CuCP- and RB19-based stamps after treatment for 23 days (stored at $4^{\circ} \mathrm{C}$ for 14 days and then exposed to sunlight for 9 days). (b) Histograms showing the stabilities for the typical SERS band signals across each dye-based SERS stamp for the various SERS stamps after 23 daytreatment based on different dyes. Error bars indicate standard derivation from three position-independent measurements. 